\title{
Neurofitter: a parameter tuning package for a wide range of electrophysiological neuron models
} Werner Van Geit ${ }^{1}$, Pablo Achard ${ }^{* 1}$ and Erik De Schutter ${ }^{1,2}$

Address: ${ }^{1}$ Lab Theoretical Neurobiology, University of Antwerp, Antwerp, Belgium and ${ }^{2}$ Computational Neuroscience Unit, Okinawa Institute of Science and Technology, Okinawa, Japan

Email: Pablo Achard* - pablo@tnb.ua.ac.be

* Corresponding author

from Sixteenth Annual Computational Neuroscience Meeting: CNS*2007

Toronto, Canada. 7-12 July 2007

Published: 6 July 2007

BMC Neuroscience 2007, 8(Suppl 2):P5 doi:10.1 I86/147I-2202-8-S2-P5

(C) 2007 Van Geit et al; licensee BioMed Central Ltd.

One of the major tasks of a neuroscientist who is developing a neuron model is to find suitable values for all the parameters of the model. This is, in general, a very complex job that can take a lot of time and that requires a lot of know-how when the parameter tuning is done by hand.
We have developed a software tool called Neurofitter that can be used to automate the process of parameter searching for neuron models. The user has to provide time series data recorded during an experiment in the form of traces. Neurofitter will then run the computer model several

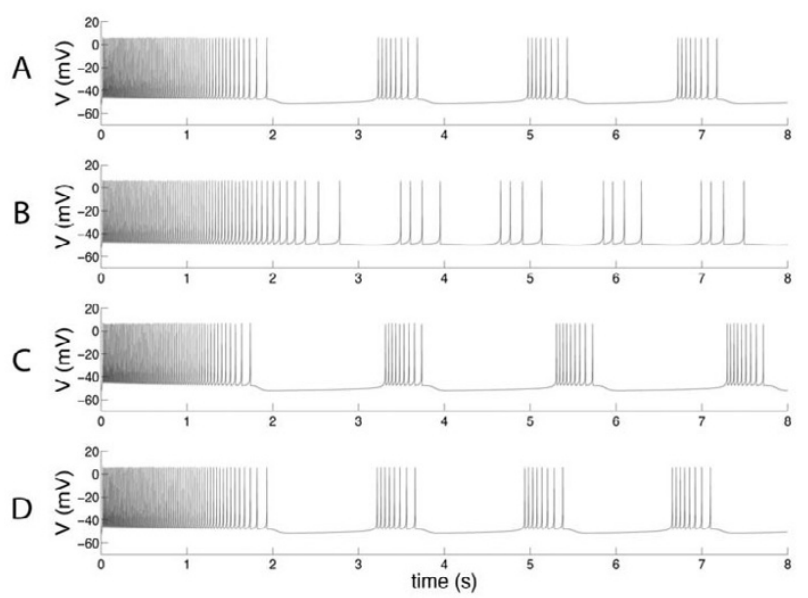

Figure I

Voltage traces showing output of a simple single-compartmental model of a rhythm generating neuron in the pre-Bötzinger complex [3]. A. Reference traces used to fit the model to. B. A trace showing the output generated by increasing the persistent sodium current conductance by only $20 \%$ compared to the original data. C. Result obtained after automatic parameter fitting using Evolutionary Strategies D. Result found by a Mesh Adaptive Search that started with the best result obtained using Evolutionary Strategies. 
times with different sets of values for the model parameters and will compare model output traces with the experimental data traces using the phase-plane trajectory method [1]. This way Neurofitter maps every set of parameters values onto a fitness value that shows how well a model is able to reproduce the experimental data. This transforms the search for optimal parameters into a problem that can be solved with general optimization algorithms. The algorithms used by Neurofitter include Evolutionary Strategies, Particle Swarm Optimization and Mesh Adaptive Search. We will show some results obtained using the method to fit a single compartmental model, a simple network model and a complicated model of a Purkinje cell [2]. The source code can be freely downloaded from Sourceforge http://neurofitter.source forge.net

\section{References}

I. Le Masson G, Maex R: Introduction to equation solving and parameter fitting. In: Computational neuroscience: realistic modeling for experimentalists. I st edition. Edited by: De Schutter E. United Kingdom: CRC Press; 200 I:I-24.

2. Achard $P$, De Schutter E: Complex parameter landscape for a complex neuron model. PLoS Comput Biol 2006, 2(7):e94.

3. Butera RJ, Rinzel J, Smith JC: Models of respiratory rhythm generation in the pre-Bötzinger complex. I. Bursting pacemaker neurons. J Neurophysiol 1999, 82:382-97.

Publish with Bio Med Central and every scientist can read your work free of charge

"BioMed Central will be the most significant development for disseminating the results of biomedical research in our lifetime. " Sir Paul Nurse, Cancer Research UK

Your research papers will be:

- available free of charge to the entire biomedical community

- peer reviewed and published immediately upon acceptance

- cited in PubMed and archived on PubMed Central

- yours - you keep the copyright

Submit your manuscript here:

http://www.biomedcentral.com/info/publishing_adv.asp 